\title{
Changes in transcutaneous oxygen tension during exercise in pulmonary emphysema
}

\author{
JA HUGHES, BJ GRAY, DCS HUTCHISON \\ From the Chest Unit, King's College Hospital Medical School, London
}

ABSTRACT Continuous measurements of transcutaneous oxygen tension $(\mathrm{tcPO})$ were made in 23 patients with radiological evidence of emphysema, at rest and during a maximal progressive exercise test. $\mathrm{tcPO}_{2}$ during the final phase of exercise was compared with $\mathrm{tcPO} \mathrm{P}_{2}$ at rest; the mean change (exercising minus resting value) in $\mathrm{tcPO}_{2}(\Delta \mathrm{tcPO})$ was $-0.8 \mathrm{~mm} \mathrm{Hg}$ (SD 10.5 , range -18 to +25$)(-0 \cdot 1 \mathrm{kPa}(\mathrm{SD} 1 \cdot 4$, range $-2 \cdot 4$ to $+3 \cdot 3)) . \Delta \mathrm{tcPo}_{2}$ was correlated with: resting arterial oxygen tension $\left(\mathrm{PaO}_{2}\right)(\mathrm{r}=0.606, \mathrm{p}<0.005)$; resting arterial carbon dioxide tension $\left(\mathrm{PaCO}_{2}\right)(\mathrm{r}=-0.691, \mathrm{p}<0.001) ; \mathrm{FEV}_{1} \%$ predicted $(\mathrm{r}=0.688, \mathrm{p}<0.001)$; vital capacity $\%$ predicted $(r=0.543, p<0.01)$; and transfer factor (TLCO) \% predicted $(r=0.604, p<0.005)$. There was no significant difference between the $\Delta \mathrm{tcPO}_{2}$ of 10 patients who regularly produced sputum and of 13 patients with no sputum. $\Delta \mathrm{tcPO}_{2}$ appears to be more closely related to the severity of emphysema than to the presence or absence of chronic bronchitis. Pretreatment with fenoterol aerosol resulted in an increased work load in three out of 10 patients. Overall there was no change in $\Delta \mathrm{tcPO}_{2}$. In all except one patient there was a rise in $\mathrm{tcPO}$ after the end of exercise. In the 11 patients whose $t c \mathrm{PO}_{2}$ fell during exercise, $\mathrm{tcPO}_{2}$ returned to the resting value within two minutes of the cessation of exercise; this was followed by a further rise beyond the resting value, and a single postexercise arterial sample is therefore a poor indicator of the response of $\mathrm{PaO}_{2}$ to exercise. Measurement of $t c \mathrm{PO}_{2}$ is of value in following rapid changes in $\mathrm{PaO}_{2}$ during and after exercise and avoids the necessity for an indwelling arterial cannula.

Changes in arterial oxygen tension $\left(\mathrm{PaO}_{2}\right)$ during exercise in patients with chronic airflow obstruction were reported by Jones, ${ }^{1}$ who showed that patients with emphysema tended to develop further hypoxaemia during exercise whereas there was a rise in $\mathrm{PaO}_{2}$ in patients who had a similar degree of airflow obstruction but no emphysema. There has subsequently been much discussion of the possible physiological mechanisms underlying these findings. We have therefore carried out a similar study of the exercise induced blood gas changes in patients with emphysema of a wide range of severity with and without chronic bronchitis.

Inhaled bronchodilator agents have been shown to produce appreciable improvement in vital capacity in emphysematous patients at rest, ${ }^{23}$ though the improvement in exercise capacity is relatively small. ${ }^{4}$

Address for reprint requests: Dr DCS Hutchison, Chest Unit, King's College Hospital, London SE5 8RX.

Accepted 13 January 1984
In this study we have taken advantage of the opportunity to investigate the effects of the $\beta_{2}$ adrenergic agent fenoterol on exercise induced changes in blood gases.

During exercise $\mathrm{PaO}_{2}$ is commonly monitored by intermittent direct sampling from an arterial cannula or indirectly on the basis of capillary samples from the warmed earlobe. Non-invasive monitoring techniques include the ear oximeter for the estimation of arterial oxygen saturation and the transcutaneous oxygen electrode, which we have used in this study.

The transcutaneous oxygen electrode ${ }^{56}$ is applied directly to the skin surface and incorporates a thermostatically controlled heater designed to promote dilatation and arterialisation of the local capillary circulation. The method has been used predominantly in the intensive care of newborn infants, ${ }^{78}$ where it gives reliable results, and it has been shown ${ }^{910}$ to provide a good estimate of $\mathrm{PaO}_{2}$ in adult patients. A close relationship between transcutaneous oxygen tension $\left(\mathrm{tcPO}_{2}\right)$ and $\mathrm{PaO}_{2}$ has been 
shown" in normal adults and in children with chronic lung disease, and a further objective of this study was to ascertain whether measurement of $\mathrm{tcPO}_{2}$ is of value in the assessment of blood gas changes during exercise in adults with chronic airflow obstruction.

\section{Methods}

Twenty three men with radiological evidence of pulmonary emphysema ${ }^{12}$ were studied. The patients gave informed consent and the project was approved by the King's College Hospital ethical committee. Thirteen patients (group A) produced little or no sputum and 10 (group B) had produced sputum for sufficient time to satisfy the Medical Research Council criteria for simple chronic bronchitis. ${ }^{13}$

\section{STUDY 1}

The patients rested for 30 minutes after arrival at the laboratory; the $\mathrm{FEV}_{1}$, relaxed vital capacity (VC), and inspiratory capacity were then measured with a Bernstein spirometer. Transfer factor for carbon monoxide (TLCO) and transfer coefficient (KCO) were measured by the single breath method (PK Morgan transfer test). Total lung capacity (TLC) and residual volume (RV) were derived from the functional residual capacity (FRC), which was measured with a Collins 09001 whole body plethysmograph. Predicted values were obtained from tables prepared by Cotes. ${ }^{14}$

Transcutaneous oxygen tension was measured by the polarographic method by means of a platinum electrode (Drägerwerk, Lübeck, West Germany) heated to $45^{\circ} \mathrm{C}$ and applied to the skin surface over the biceps muscle; the design of the electrode is similar to that described by Huch et al..$^{5}$ The output of the electrode could be read digitally or displayed on a chart recorder. Details of the calibration procedure are given at the end of this section.

A progressive exercise test was performed on an electrically braked cycle ergometer. The $\mathrm{tcPO}_{2}$ was monitored for at least one minute while the patient was seated at rest on the cycle ergometer, until a constant reading was obtained ( $\mathrm{tcPO} \mathrm{PO}_{2}$ : rest) and was monitored throughout the exercise study and for 30 minutes after the end of exercise. $\mathrm{tcPO}_{2}$ was noted at the instant the patient stopped exercise $\left(\mathrm{tcPO}_{2}\right.$ : end ex) and when it reached the highest value during the postexercise period $(\mathrm{tcPO})_{2}$ : post ex). The $\mathrm{tcPO}_{2}$ values at these specific points were read from the digital meter.

During the first minute of exercise no additional work load was applied; thereafter the load was increased by 10 watts every minute until the maxi- mum load was attained. The electrocardiogram was displayed throughout the procedure but no dysrhythmic or ischaemic episodes were observed. Ten patients included in study 1 received two puffs from a placebo aerosol 30 minutes before the start of exercise as a preliminary to study 2 .

\section{STUDY 2}

Ten patients who had performed study 1 took part in a single blind study to compare the effects of fenoterol and placebo aerosols on $\mathrm{tcPO}_{2}$ during exercise. In these patients the placebo aerosol was administered as part of study 1 . Forty five minutes after the end of study $1, \mathrm{FEV}_{1}$ and VC were measured before and 30 minutes after two puffs ( $400 \mu \mathrm{g})$ from a fenoterol metered dose aerosol canister. The progressive exercise test was then repeated, $\mathrm{tcPO}_{2}$ being monitored at rest and during exercise as in study 1 . The electrode remained in place throughout both studies. The drift was never more than $5 \%$ in any study and in most it was substantially less; the measurements were therefore not corrected for drift.

CALIBRATION OF tcPO ${ }_{2}$ ELECTRODE

Before each study the electrode was calibrated in vitro at two points, sodium sulphite solution (zero oxygen tension) and atmospheric air being used. ${ }^{9}$ The electrode was then attached to the patient and after an interval of not less than 30 minutes (by which time a steady $\mathrm{tcPO}_{2}$ reading had been obtained) an arterial blood sample was taken by brachial or radial puncture. Arterial carbon dioxide tension $\left(\mathrm{PaCO}_{2}\right)$ and $\mathrm{PaO}_{2}$ were measured immediately (Dow-Corning analyser, type 165). The gain control of the $\mathrm{tcPO}_{2}$ system was then altered so that the output corresponded to the measured $\mathrm{PaO}_{2}$; we have called this procedure in vivo calibration. At the end of the study, the in vitro calibration against atmospheric air was repeated and shown to correspond to the initial value, after allowance had been made for any alteration in gain control necessitated by the in vivo calibration procedure.

We have shown ${ }^{10}$ by simultaneous measurement of $\mathrm{PaO}_{2}$ and $\mathrm{tcPO}_{2}$ in 14 patients that this in vivo calibration procedure considerably improves the accuracy of $\mathrm{tcPO}_{2}$ measurement. For 55 data points over the range $50-120 \mathrm{~mm} \mathrm{Hg}$ we obtained the relationship

$$
\begin{gathered}
\mathrm{tcPo}_{2}(\mathrm{~mm} \mathrm{Hg})=0.98 \mathrm{PaO}_{2}+1.61 \\
(95 \% \text { confidence limits } \pm 6.6 \mathrm{~mm} \mathrm{Hg}) .
\end{gathered}
$$

An example of the close relationship between $\mathrm{PaO}_{2}$ and $\mathrm{tcPO}_{2}$ is shown in figure 1 ; during the postexercise rise in arterial $\mathrm{PO}_{2}$ the response of the $\mathrm{tcPO}_{2}$ electrode was complete within two minutes. The 


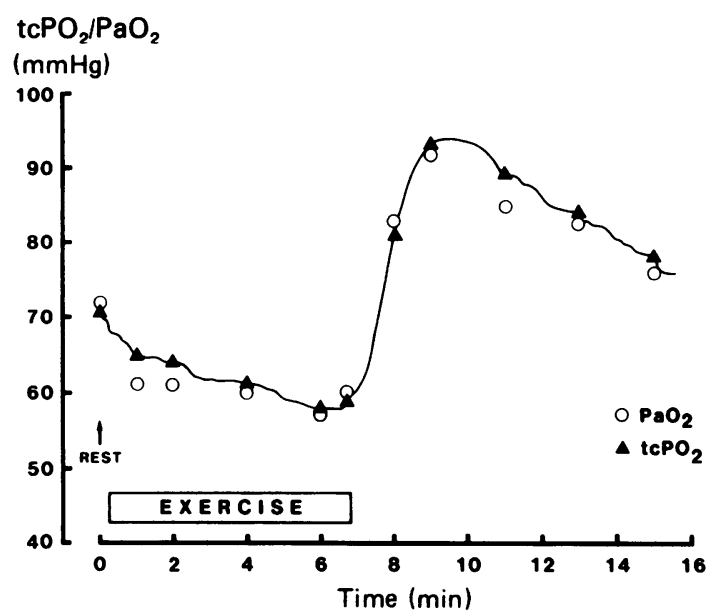

Fig 1 Continuous record of transcutaneous oxygen tension (tcPo $)_{2}$ from a Radiometer electrode in a patient with emphysema (not part of this study). The in vivo calibration procedure was used. Circles: arterial $\mathrm{PO}_{2}$ measured on samples drawn from indwelling arterial cannula. Triangles: tcPO $\mathrm{O}_{2}$ read from digital meter at mid-point of arterial sampling. The patient exercised on a cycle ergometer, the work load being increased to maximum by 10 watts every minute. Conversion: Traditional to SI units-Oxygen tension: $1 \mathrm{~mm} \mathrm{Hg} \approx 0.133 \mathrm{kPa}$.

above regression equation and the results illustrated in figure 1 were obtained with the Radiometer electrode rather than the Dräger electrode used for the main part of this study, but we and others ${ }^{1516}$ have found that they have similar characteristics. Results similar to those shown in figure 1 have been obtained in a further five patients studied in this laboratory. ${ }^{17}$

The significance of differences between groups was assessed by means of a paired or unpaired Student's $t$ test as appropriate.

\section{Results}

\section{STUDY 1}

The age and lung function indices of the patients in groups A (no sputum) and B (chronic bronchitis) are shown in table 1 . Patients in group $B$ were significantly older $(p<0.02)$ than those of group $A$. $\mathrm{FEV}_{1}, \mathrm{VC}$, TLCO, and KCO (as percentages of predicted values) were all lower in group $B$ than in group $\mathbf{A}$, but in no instance were the differences significant at the $5 \%$ level. There was no significant difference between the groups in resting $\mathrm{PaO}_{2}$ or $\mathrm{PaCO}_{2}$ (table 2).

The changes in $\operatorname{tcPO}_{2}\left(\Delta \mathrm{tcPO}_{2}\right)$ are shown in table 2 and two examples of tcPO $\mathrm{PO}_{2}$ tracings in figures 2 and 3. In group $\mathrm{A} \mathrm{tcPO}$ rose on average by 1.4 (SD
Table 1 Lung function in patients without sputum (group $A)$ and patients with chronic bronchitis (group B): mean percentages (with standard deviations in parentheses) of predicted normal values

\begin{tabular}{|c|c|c|}
\hline & Group $A$ & Group B \\
\hline $\begin{array}{l}\text { Number* } \\
\text { Age (y) } \\
\text { FEV } \\
\text { VC } \\
\text { TLC } \\
\text { RV } \\
\text { TLco } \\
\text { Kco }\end{array}$ & $\begin{array}{l}13 \\
57 \cdot 2 \quad(9 \cdot 3) \\
45 \cdot 8(27 \cdot 2) \\
76.9(21 \cdot 0) \\
119.2(10 \cdot 2) \\
200.1(39.7) \\
61.9(22 \cdot 3) \\
78.2(22.3)\end{array}$ & 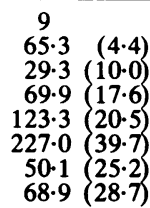 \\
\hline
\end{tabular}

*Total lung capacity and residual volume were measured in 10 patients of group $\mathbf{A}$ and nine patients of group $\mathbf{B}$.

VC-vital capacity; TLC-total lung capacity; RV-residual volume; TLCo-transfer factor for carbon monoxide; Kcotransfer coefficient.

10.9) $\mathrm{mm} \mathrm{Hg}$ by the end of the exercise; in group $B$ it fell by $3.7(9.3) \mathrm{mm} \mathrm{Hg}$. In neither group A nor group $\mathrm{B}$ was $\Delta \mathrm{tcPO}{ }_{2}$ significantly different from zero and there was no significant difference between the groups.

With the exception of one patient in group A, all patients showed a rise in $\mathrm{tcPO}_{2}$ after exercise (table 2 ). The mean difference between $\mathrm{tcPO}_{2}$ at the end of the exercise and $\mathrm{tcPO}_{2}$ at the peak of the postexercise rise was $18.8 \mathrm{~mm} \mathrm{Hg}$ in group $A$ and $19.7 \mathrm{~mm} \mathrm{Hg}$ in group $\mathrm{B}$; there was no significant difference between the two groups. The average interval between the end of the exercise and the maximum postexercise $\mathrm{tcPO}_{2}$ was $4 \frac{1}{2}$ minutes (range 3-61/2 minutes). Thirty minutes after the end of exercise the mean $\mathrm{tcPO}_{2}$ was still significantly above the initial resting value. The change in $\mathrm{tcPO}_{2}$ during exercise $\left.(\Delta \mathrm{tcPO})_{2}\right)$, defined as $\mathrm{tcPO}_{2}$ : end ex minus $\mathrm{tcPO}_{2}$ : rest, was found to be significantly correlated with the arterial blood gas tensions and most lung function indices (table 3 ) when data from both groups were considered together. There was, however, no significant correlation between $\Delta \mathrm{tcPO}_{2}$ and TLC.

STUDY 2

At rest the placebo aerosol had no significant effect ( $p>0.05$ ) on FEV, or VC in the 10 patients studied. After administration of fenoterol the mean FEV increased by 0.16 litres $(p<0.02)$ and the mean VC by $0.621(\mathrm{p}<0.01)$. The mean $\mathrm{tcPO}_{2}$ increased by $5.3 \mathrm{~mm} \mathrm{Hg}(\mathrm{p}<0.02)$.

Overall there was no significant change in $\mathrm{tcPO}_{2}$ during exercise either after placebo or after fenoterol (table 4). There was on average no significant difference between the placebo and fenoterol responses $(p>0.05)$. There was no significant difference $(p>0.05)$ in fenoterol 
Table 2 Resting arterial blood gases and changes in transcutaneous oxygen tension $\left(\Delta t c \mathrm{Po}_{2}\right)$ during and after exercise in patients of groups $A$ and $B$

\begin{tabular}{|c|c|c|c|c|}
\hline \multirow[t]{2}{*}{ Patient No } & \multicolumn{2}{|c|}{ Resting blood gas tensions ( $\mathrm{mm} \mathrm{Hg}$ ) } & \multicolumn{2}{|l|}{$\Delta c \mathrm{PO}_{2}(\mathrm{~mm} \mathrm{Hg})$} \\
\hline & $\mathrm{PaO}_{2}$ & $\mathrm{PaCO}_{2}$ & $\begin{array}{l}\text { "End exercise" } \\
\text { minus "rest" }\end{array}$ & $\begin{array}{l}\text { "Post exercise peak" } \\
\text { minus "end exercise" }\end{array}$ \\
\hline $\begin{array}{l}\text { GROUP A } \\
1 \\
2 \\
3 \\
4 \\
5 \\
6 \\
7 \\
8 \\
9 \\
10 \\
11 \\
12 \\
13\end{array}$ & $\begin{array}{l}61 \\
77 \\
60 \\
67 \\
74 \\
68 \\
70 \\
70 \\
78 \\
61 \\
73 \\
65 \\
56\end{array}$ & $\begin{array}{l}49 \\
33 \\
40 \\
39 \\
40 \\
45 \\
41 \\
35 \\
35 \\
39 \\
39 \\
35 \\
47\end{array}$ & $\begin{array}{r}-18 \\
+2 \\
-4 \\
+1 \\
+10 \\
+7 \\
-3 \\
+6 \\
+25 \\
0 \\
-3 \\
+9 \\
-14\end{array}$ & $\begin{array}{r}+29 \\
+17 \\
+15 \\
+18 \\
0 \\
+12 \\
+25 \\
+10 \\
+16 \\
+18 \\
+22 \\
+25 \\
+38\end{array}$ \\
\hline $\begin{array}{l}\text { Mean } \\
\text { SD }\end{array}$ & $\begin{array}{r}67 \cdot 7 \\
6.9\end{array}$ & $\begin{array}{r}39 \cdot 8 \\
4 \cdot 8\end{array}$ & $\begin{array}{l}+1.4(\mathrm{NS}) \\
10.9\end{array}$ & $+\underset{9.4}{18.8}(\mathrm{p}<0.001)$ \\
\hline $\begin{array}{l}\text { GROUP B } \\
1 \\
2 \\
3 \\
4 \\
5 \\
6 \\
7 \\
8 \\
9 \\
10\end{array}$ & $\begin{array}{l}80 \\
63 \\
69 \\
61 \\
73 \\
61 \\
67 \\
60 \\
55 \\
56\end{array}$ & $\begin{array}{l}34 \\
38 \\
44 \\
49 \\
34 \\
39 \\
36 \\
45 \\
35 \\
48\end{array}$ & $\begin{array}{l}+10 \\
+4 \\
-17 \\
-14 \\
-3 \\
+1 \\
+8 \\
-12 \\
-6 \\
-8\end{array}$ & $\begin{array}{l}+22 \\
+13 \\
+22 \\
+26 \\
+23 \\
+9 \\
+6 \\
+27 \\
+23 \\
+26\end{array}$ \\
\hline $\begin{array}{l}\text { Mean } \\
\text { SD }\end{array}$ & $\begin{array}{r}64 \cdot 5 \\
7 \cdot 8\end{array}$ & $\begin{array}{r}40 \cdot 2 \\
5.8\end{array}$ & $\begin{array}{l}-3 \cdot 7 \text { (NS) } \\
9 \cdot 3\end{array}$ & $+\underset{7.5}{19.7}(p<0.001)$ \\
\hline $\begin{array}{l}\text { Groups A and B together } \\
\text { Mean } \\
\text { SD }\end{array}$ & $\begin{array}{l}(\mathbf{N}=23 \\
66 \cdot 3 \\
7 \cdot 3\end{array}$ & $\begin{array}{r}40 \cdot 0 \\
5 \cdot 2\end{array}$ & $\begin{array}{l}-0.8(\mathrm{NS}) \\
10.3\end{array}$ & $+\underset{8.5}{+19.2(p<0.001)}$ \\
\hline $\begin{array}{l}\text { Significance of difference } \\
\text { between groups A and B } \\
\text { (unpaired } t \text { test) }\end{array}$ & NS & NS & NS & NS \\
\hline
\end{tabular}

Values for postexercise peak minus end exercise $\mathrm{tcPO}_{2}$ significantly different from zero in both group $\mathrm{A}$ and group $\mathrm{B}$.

*Paired $t$ test.

Conversion: Traditional to SI units-Oxygen tension: $1 \mathrm{~mm} \mathrm{Hg} \approx 0.133 \mathrm{kPa}$.

NS-not significantly different from zero (either group or both together).

response between groups $A$ and $B$, though the number of patients was small.

Three patients (A2, A3, and B3) achieved a greater work load after fenoterol; for the sake of comparison therefore $\mathrm{tcPO}_{2}$ : end ex for the fenoterol study was taken not at the point of the maximal load but for the load equal to the maximum load attained during the placebo exercise test.

No significant correlation $(r=0.403, p>0.1)$ was observed between the change in VC after fenoterol and the effect of fenoterol on the $\mathrm{tcPO}_{2}$ response to exercise (that is, $\Delta \mathrm{tcPO}{ }_{2}$ : fenoterol minus $\Delta \mathrm{tcPO} \mathrm{P}_{2}$ : placebo).

\section{Discussion}

Conflicting results have been obtained concerning the changes in $\mathrm{PaO}_{2}$ during exercise in patients with chronic airflow obstruction. In one of the early studies Jones' investigated two groups of patients; the first (group A) had radiological evidence of emphysema or lung function values which strongly supported that diagnosis, and the second (group B) had severe airflow obstruction but no evidence of emphysema. There was a mean fall in $\mathrm{PaO}_{2}$ of $11.6 \mathrm{~mm} \mathrm{Hg}$ in group $\mathrm{A}$, but in contrast there was a mean rise of $6 \mathrm{~mm} \mathrm{Hg}$ in group $B$. 


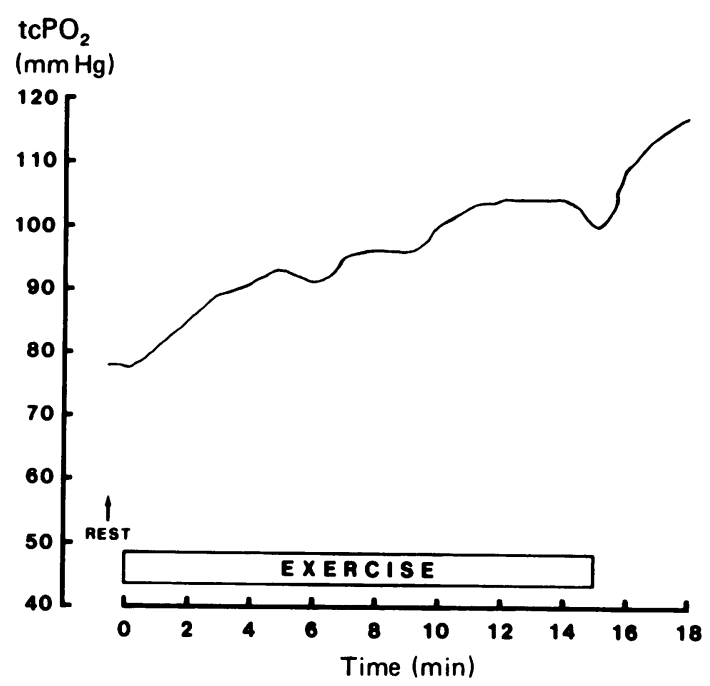

Fig 2 Continuous record of transcutaneous oxygen tension $\left(\mathrm{tcPO} \mathrm{O}_{2}\right.$ before, during, and after the progressive exercise test for patient 9, group $A$. The work load was increased by 10 watts every minute. There is a continuous increase in $\mathrm{CPO}_{2}$ during exercise and a further increase after exercise. Values read from the digital meter at specific points are given in table 2. Conversion: Traditional to SI units-Oxygen tension: $1 \mathrm{~mm} \mathrm{Hg} \approx 0.133 \mathrm{kPa}$.

Filley et $a^{18}$ also investigated two groups of patients who were selected on clinical grounds. The arterial oxygen saturation fell with exercise by $4 \%$ in their "emphysematous" group but fell by $8 \%$ in

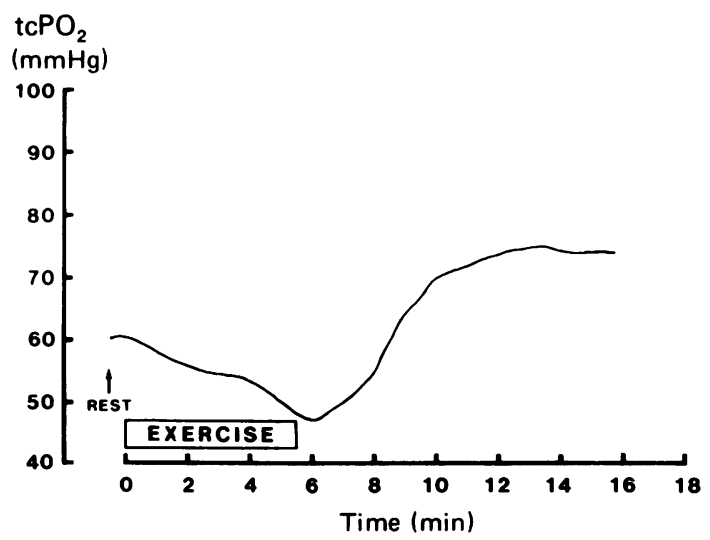

Fig 3 Continuous record of transcutaneous oxygen tension (tcPo $)_{2}$ (as in fig 1) from patient 8 , group $B$. The value of tcPO $\mathrm{O}_{2}$ falls steadily during exercise with a substantial increase during the postexercise period. Conversion: Traditional to SI units-Oxygen tension: $1 \mathrm{~mm} \mathrm{Hg}$ $\approx 0.133 \mathrm{kPa}$.
Table 3 Correlation coefficients of changes in transcutaneous oxygen tension ( $\triangle \mathrm{tcPO} \mathrm{O}_{2}$ ) ("end exercise" minus "rest") in groups $A$ and B combined with arterial oxygen $\left(\mathrm{PaO}_{2}\right)$ and carbon dioxide tensions ( $\left.\mathrm{PaCO}_{2}\right)$ and lung function indices (as percentages of predicted values)

\begin{tabular}{llll}
\hline & $n$ & $\begin{array}{c}\text { Correlation } \\
\text { coefficient }\end{array}$ & $p$ \\
\hline $\mathrm{PaO}_{2}$ at rest & 23 & 0.606 & $<0.005$ \\
$\mathrm{PaCO}_{2}$ at rest & 23 & -0.691 & $<0.001$ \\
$\mathrm{FEV}_{1}$ & 23 & 0.688 & $<0.001$ \\
VC & 23 & 0.543 & $<0.01$ \\
TLC & 19 & 0.004 & NS \\
RV & 19 & -0.452 & $\approx 0.05$ \\
TLco & 23 & 0.604 & $<0.005$ \\
Kco & 23 & 0.447 & $<0.05$ \\
\hline
\end{tabular}

Abbreviations as in table 1 .

their "bronchitic" subjects, who had evidence of heart failure and polycythaemia. Ten of the "bronchitic" patients subsequently had a postmortem $\subseteq$ examination; eight were found to have severe $\overparen{\mathbb{D}}$ emphysema, perhaps explaining in part why the $\vec{\theta}$ findings are not in agreement with those of Jones. ${ }^{1}$

Emmanuel and Moreno, ${ }^{19}$ in a study of patients who had radiological evidence of emphysema, observed a rise in arterial oxygen saturation in those with milder disease but a fall in those with more severe disease. Minh et $a^{20}$ selected patients with chronic airflow obstruction (without definite evidence on the presence or absence of emphysema) and showed that those patients in whom $\mathrm{PaO}_{2}$ fell with exercise had more severe impairment of lung function than did those in whom $\mathrm{PaO}_{2}$ rose or remained unchanged.

We selected patients who had definite radiological evidence of emphysema and have shown that in the milder cases there is a rise in $\mathrm{PaO}_{2}$ with exercise, whereas there is a fall in the more severely affected patients. We have not, however, studied patients similar to those in Jones's group B, who had airflow obstruction without emphysema.' Such patients are often described as bronchitic, but it is clear from our results that the presence of simple chronic bronchitis (persistent sputum production) makes no difference to the exercise induced changes in $\mathrm{tcPO}_{2}$ in emphysema. The commonly stated view that so called bronchitic patients show a rise in $\mathrm{PaO}_{2}$ with exercise while "emphysematous" patients show a fall is an oversimplification of the true position.

The type of exercise may also be important in determining the blood gas changes, and this has seldom been taken into account. Cohn and Donoso ${ }^{21}$ showed that there was little change in $\mathrm{PaO}_{2}$ during steady state treadmill exercise, although there was an obvious fall during a step test, which is a more strenuous form of exercise similar to the progressive test used by us. Tests at maximal exercise capacity 
Table 4 Study 2: comparison of the effects of fenoterol and placebo aerosols on the change in transcutaneous oxygen tension $\left(\Delta t c \mathrm{Po}_{2}\right)$ in response to exercise

\begin{tabular}{|c|c|c|c|c|c|c|c|c|}
\hline \multicolumn{2}{|l|}{ Patient } & \multicolumn{3}{|c|}{$t c \mathrm{PO}_{2}(\mathrm{~mm} \mathrm{Hg}):$ placebo } & \multicolumn{3}{|c|}{$t_{c P O}(m m ~ H g):$ fenoterol ${ }^{*}$} & \multirow{2}{*}{$\begin{array}{l}\Delta t c P O_{2} \\
\text { fenotero } \\
\text { minus } \\
\text { placebo }\end{array}$} \\
\hline Group & No & Rest & End ex & $\begin{array}{l}\text { End ex } \\
\text { minus rest }\end{array}$ & Rest & End ex & $\begin{array}{l}\text { End ex } \\
\text { minus rest }\end{array}$ & \\
\hline $\begin{array}{l}\text { A } \\
\text { A } \\
\mathbf{A} \\
\mathbf{A} \\
\mathbf{A} \\
\mathbf{A} \\
\mathbf{B} \\
\mathbf{B} \\
\mathbf{B} \\
\mathbf{B}\end{array}$ & $\begin{array}{l}2 \\
3 \\
5 \\
6 \\
7 \\
8 \\
2 \\
3 \\
4 \\
7\end{array}$ & $\begin{array}{l}76 \\
57 \\
72 \\
66 \\
72 \\
73 \\
74 \\
70 \\
67 \\
69\end{array}$ & $\begin{array}{l}78 \\
53 \\
82 \\
73 \\
69 \\
79 \\
78 \\
53 \\
53 \\
77\end{array}$ & $\begin{array}{l}+2 \\
+4 \\
+10 \\
+7 \\
+3 \\
+6 \\
+4 \\
-17 \\
-14 \\
+8\end{array}$ & $\begin{array}{l}83 \\
60 \\
79 \\
76 \\
73 \\
88 \\
76 \\
69 \\
65 \\
80\end{array}$ & $\begin{array}{l}75 \\
57 \\
86 \\
74 \\
78 \\
86 \\
82 \\
59 \\
58 \\
82\end{array}$ & $\begin{array}{l}-8 \dagger \\
-\quad 3 \dagger \\
+7 \\
-2 \\
+5 \\
-2 \\
+\quad 6 \\
-10 \dagger \\
-\quad 7 \\
+\quad 2\end{array}$ & $\begin{array}{l}-10 \\
+\quad 1 \\
-\quad 3 \\
-\quad 9 \\
+\quad 8 \\
+\quad 8 \\
+\quad 2 \\
+7 \\
+\quad 6\end{array}$ \\
\hline \multicolumn{2}{|c|}{$\begin{array}{l}\text { Mean } \\
\text { SD } \\
\mathrm{p} \text { (difference from zero) } \\
\quad \text { (paired } t \text { test) }\end{array}$} & $\begin{array}{r}69.6 \\
5.4\end{array}$ & $\begin{array}{l}69.5 \\
11.9\end{array}$ & $\begin{array}{l}-\quad 0.1 \\
\text { NS }\end{array}$ & $\begin{array}{r}74.9 \\
8.4\end{array}$ & $\begin{array}{l}73.7 \\
11.6\end{array}$ & $\begin{array}{l}-\quad 1 \cdot 2 \\
\text { NS }\end{array}$ & $\begin{array}{l}-\quad \begin{array}{l}1.1 \\
7.0\end{array} \\
\text { NS }\end{array}$ \\
\hline
\end{tabular}

Placebo $v$ fenoterol (paired $t$ test): rest, $\mathrm{p}<0.025$; end exercise (end ex), $\mathrm{p}<0.005$.

*The change in transcutaneous oxygen tension $\left(\Delta t \mathrm{CPO}_{2}\right)$ for fenoterol refers to value obtained at same work load as placebo maximal load. †Three subjects who pertormed more work atter tenoterol.

NS-not significant at $5 \%$ level.

Conversion: Traditional to SI units-Oxygen tension: $1 \mathrm{~mm} \mathrm{Hg} \approx 0.133 \mathrm{kPa}$.

would be expected to demonstrate changes in $\mathrm{PaO}_{2}$ or $\mathrm{tcPO}_{2}$ more readily than submaximal tests.

Early interest in the physiological reasons for the exercise induced changes in $\mathrm{PaO}_{2}$ centred around the differing responses seen in the "emphysematous" and "chronic bronchitic" types of patient. Jones ${ }^{1}$ postulated that in the bronchitic patient the increase in $\mathrm{PaO}_{2}$ was brought about by a rise in the ventilation of lung units with a low ventilation:perfusion ( $\dot{V} / Q)$ ratio. It was subsequently confirmed ${ }^{22}$ by the multiple inert gas infusion technique that in such patients there is considerable blood flow to units with a very low $\dot{V} / Q$ ratio $(0.03-0.01)$; arterial $\mathrm{PO}_{2}$ would be sensitive to changes in the ventilation of such units.

In emphysema, however, the position is very different. ${ }^{22}$ There is substantial ventilation of units with a high $\dot{V} / Q$ ratio, but no evidence of the low $\dot{V} / Q$ units found in the group $B$ patients. It could be argued that low $\dot{V} / Q$ units, or even a true shunt, could come into being with heavy exercise in emphysema; but it seems more likely that diffusion limitations will begin to play a part. In emphysema the destruction of the lung parenchyma brings about an enlargement in the terminal air spaces (and thus a longer diffusion path), a reduction in the surface area of the alveolar-capillary membrane, and a reduction in the pulmonary capillary volume. The last of these changes would lead to a reduction in the transit time of blood through the capillary and this effect would be greater with increase of pulmonary blood flow. If transit time is severely reduced, the oxygen tension of the pulmonary capillary blood will not have time to reach equilibrium with alveolar gas. It has been calculated ${ }^{23}$ that a fourfold reduction in diffusing capacity would be required to produce a significant fall in $\mathrm{PaO}_{2}$ by this mechanism. The steady fall in $\mathrm{tcPO}_{2}$ with increasing work load seen in most of our more severely affected patients appears to be consistent with the hypothesis that exercise induced hypoxaemia is at least partly due to diffusion limitation associated with a reduced transit time; an increase in the dispersion of transit times would further reduce $\mathrm{PaO}_{2}$.

The onset of relative alveolar hypoventilation during exercise might also account in part for a reduction in $\mathrm{PaO}_{2}$, but we were not able to measure $\mathrm{PaCO}_{2}$ in this study. In previous studies, ${ }^{1} 182021$ however, a rise in $\mathrm{PaCO}_{2}$ during exercise occurred in relatively few emphysematous patients and hypoventilation is therefore not likely to be an important contributor to the fall in $\mathrm{PaO}_{2}$.

Administration of bronchodilator aerosols to emphysematous patients has been shown ${ }^{24}$ to produce a moderate increase in 12 minute walking distance, although it may fail to improve maximal exercise tolerance during a progressive test on a cycle ergometer. ${ }^{4}$ In the present study only three of the 10 patients (table 4) achieved a greater work load after fenoterol than after placebo. The average resting $\mathrm{tcPO}_{2}$ after fenoterol was $5.3 \mathrm{~mm} \mathrm{Hg}$ greater than after placebo $(p<0.02)$ and $4.2 \mathrm{~mm} \mathrm{Hg}$ greater than placebo after exercise $(p<0.005)$. Owing to unavoidable limitations on the study protocol, fenoterol was always administered after placebo, though the nature of the aerosols was not known to 
the patients. The precise reasons for the observed increases in $\mathrm{tcPO}_{2}$ after fenoterol are therefore not known but could include improved ventilationperfusion relationships or an effect of the first postexercise rise. Electrode drift is another possibility but this was never more than $5 \%$ over the whole study period. The fact remains that, despite the appreciable increase in VC, the results taken overall showed no difference between $\Delta \mathrm{tcPO}{ }_{2}$ values after fenoterol and after placebo, although the two patients (B3 and B4) who had the greatest fall in $\mathrm{tcPO}_{2}$ after placebo showed a much reduced fall after fenoterol. We have no evidence about the reproducibility of exercise induced changes in $\mathrm{tcPO}_{2}$ and further work is required to determine whether large falls in $\mathrm{tcPO}_{2}$ can consistently be modified by bronchodilator treatment.

Calibration of the transcutaneous $\mathrm{PO}_{2}$ electrode using atmospheric air has proved satisfactory in newborn infants ${ }^{8}$ but is less precise in adults, ${ }^{9}$ presumably owing to unpredictable variations in the thickness and metabolism of the skin and the state of the local circulation. The "in vivo" calibration method $^{10}$ used in the present study circumvents some of these sources of variation and an accurate estimate of $\mathrm{PaO}_{2}$ can be obtained by this means. We have shown that a transcutaneous electrode can reflect the blood gas changes taking place during a single progressive exercise test with reasonable accuracy (fig 1). The performance of the electrode would be acceptable for clinical purposes.

At the end of the exercise period (figs 2 and 3 ) $\mathrm{tcPO}_{2}$ underwent a rapid increase in all but one patient. To avoid arterial cannulation, the blood gas response to an exercise test is quite commonly assessed by means of a single arterial puncture after the end of the exercise, but our results show that if there is any delay in obtaining the blood sample the lowest $\mathrm{PaO}_{2}$ value will almost certainly be missed and the test invalidated. A similar conclusion was reached by Ries et al, ${ }^{25}$ who measured $\mathrm{PaO}_{2}$ via an indwelling cannula in some patients with chronic airflow obstruction; in most they observed a rapid rise in $\mathrm{PaO}_{2}$ immediately after the end of exercise. The sudden reduction of metabolic demand and the resulting rise in central venous $\mathrm{Po}_{2}$, coupled with persisting ventilatory stimulation, are factors which presumably contribute to the rapid postexercise increase in $\mathrm{PaO}_{2}$.

Any changes in skin blood flow occurring during exercise could theoretically influence tcPO ${ }_{2}$, but the close correspondence between $\mathrm{tcPO}_{2}$ and $\mathrm{PaO}_{2}$ observed in the type of patient illustrated in figure 1 suggests that this effect is not of great importance. The operating electrode temperature of $45^{\circ} \mathrm{C}$ presumably ensures maximal vasodilatation in the adja- cent skin. This method seems preferable to derivation of $\mathrm{PaO}_{2}$ from measurement of oxygen saturation by ear oximetry, as this would require simultaneous estimation of arterial $\mathrm{pH}$ and would have an unacceptable error at higher levels of oxygen saturation. ${ }^{26}$

We conclude that the transcutaneous $\mathrm{PO}_{2}$ electrode can provide a valid estimate of $\mathrm{PO}_{2}$ during exercise in emphysematous patients. It seems likely that this would hold good in normal subjects and patients with other disorders, provided that no undue vasoconstriction took place. ${ }^{9}$

We owe grateful thanks to the medical staff of WB Pharmaceuticals Ltd for financial support, to Eleanor Allan for statistical advice, to the technical staff of the chest unit, and to Mary Ewing and Catherine Barton for secretarial assistance.

\section{References}

' Jones NL. Pulmonary gas exchange during exercise in patients with chronic airway obstruction. Clin Sci 1966;31:39-50.

${ }^{2}$ Bellamy D, Hutchison DCS. The effects of salbutamol metered-dose aerosol on lung function in pulmonary emphysema. Br J Dis Chest 1981;75:190-6.

${ }^{3}$ Hughes JA, Tobin MJ, Bellamy D, Hutchison DCS. The effects of ipratropium bromide and fenoterol aerosols in patients with pulmonary emphysema. Thorax 1982;37:667-70.

${ }^{4}$ Tobin MJ, Hughes JA, Hutchison DCS. The effects of bronchodilator aerosols on exercise tolerance in emphysema: a double-blind study with ipratropium bromide and fenoterol. Eur J Respir Dis (in press).

${ }^{5}$ Huch A, Huch R, Arner B, Rooth G. Continuous transcutaneous oxygen tension measured with a heated electrode. Scand J Clin Lab Invest 1973;31:269-75.

${ }^{6}$ Eberhard P, Hammacher K, Mindt W. Methode zur kutanen Messung des Sauerstoffpartialdruckes. Biomed Tech 1973;6:216-21.

${ }^{7}$ Huch R, Lübbers DW, Huch A. Reliability of transcutaneous monitoring of arterial $\mathrm{PO}_{2}$ in newborn infants. Arch Dis Child 1974;49:213-8.

${ }^{8}$ le Souëf PN, Morgan AK, Soutter LP, Reynolds EOR, Parker D. Comparison of transcutaneous oxygen tension with arterial oxygen tension in newborn infants with severe respiratory illnesses. Pediatrics 1978; 62:692-7.

${ }^{9}$ Hutchison DCS, Rocca G, Honeybourne D. Estimation of arterial oxygen tension in adult subjects using a transcutaneous electrode. Thorax 1981;36:473-7.

${ }^{10}$ Gray BJ, Heaton RW, Henderson AF, Hutchison DCS. Single point in vivo calibration improves the accuracy of transcutaneous oxygen tension measurements in adult patients. Thorax 1983;38:712 (abstract).

" Schonfeld T, Sargent CW, Bautista D, et al. Transcutaneous oxygen monitoring during exercise stress testing. Am Rev Respir Dis 1980;121:457-62.

12 Laws JW, Heard BE. Emphysema and the chest film: a retrospective radiological and pathological study. $\mathrm{Br} J$ Radiol 1962;35:750-61. 
${ }^{13}$ Medical Research Council. Definition and classification of chronic bronchitis for clinical and epidemiological purposes. Lancet 1965; i:775-9.

${ }^{14}$ Cotes JE. Lung function: assessment and application in medicine. 4th ed. Oxford: Blackwell Scientific Publications, 1979.

${ }^{15}$ Simpson RMcD, Bryan MH. Transcutaneous oximetry. Br J Hosp Med 1982;28:269-72.

${ }^{16}$ Rithalia SVS. Non-invasive measurement of blood gases in critically ill patients. PhD thesis, University of London, 1982.

17 Gray BJ, Heaton RW, Callaghan JM, Hutchison DCS. Transcutaneous oxygen tension accurately reflects changing arterial oxygen tension during exercise. Thorax 1984;39:234 (abstract).

${ }^{18}$ Filley GF, Beckwitt HJ, Reeves JT, Mitchell RS. Chronic obstructive bronchopulmonary disease. II-Oxygen transport in two clinical types. $\mathrm{Am} \mathrm{J} \mathrm{Med}$ 1968;44:26-38.

${ }^{19}$ Emmanuel GE, Moreno F. Distribution of ventilation and blood flow during exercise in emphysema. J Appl Physiol 1966;21:1532-44.

${ }^{20}$ Minh V, Lee HM, Dolan GF, Light RW, Bell J, Vasquez P. Hypoxaemia during exercise in patients with chronic obstructive pulmonary disease. Am Rev Respir Dis 1979;120:787-94.

${ }^{21}$ Cohn JE, Donoso HD. Exercise and intrapulmonary ventilation-perfusion relationships in chronic obstructive airway disease. Am Rev Respir Dis 1967; 95:1015-25.

22 Wagner PD, West JB. Effects of diffusion impairment on $\mathrm{O}_{2}$ and $\mathrm{CO}_{2}$ time courses in pulmonary capillaries. $J$ Appl Physiol 1972;33:62-71.

${ }^{23}$ Wagner PD, Dantzker DR, Dueck R, Clausen JL, West JB. Ventilation-perfusion inequality in chronic obstructive pulmonary disease. J Clin Invest 1977; 59:203-16.

${ }^{24}$ Leitch AG, Hopkin JM, Ellis DA, Merchant S, McHardy GJR. The effect of aerosol ipratropium bromide and salbutamol on exercise tolerance in chronic bronchitis. Thorax 1978;33:711-3.

${ }^{25}$ Ries AL, Fedullo PF, Clausen JL. Rapid changes in arterial blood gas levels after exercise in pulmonary patients. Chest 1983;83:454-6.

${ }^{26}$ Saunders NA, Powles ACP, Rebuck AS. Ear oximetry: accuracy and practicability in the assessment of arterial oxygenation. Am Rev Respir Dis 1976;113:745-9. 